\title{
IMPORTED MALARIA NOTIFIED IN NEW SOUTH WALES AND THE AUSTRALIAN CAPITAL TERRITORY, INCLUDING TRENDS IN NOTIFICATIONS OF PLASMODIUM FALCIPARUM, 1989 TO 2003
}

\begin{abstract}
John Walker
Formerly with the Centre for Infectious Diseases and Microbiology at Westmead Hospital
\end{abstract}

\section{Richard Taylor}

School of Population Health

The University of Queensland

\section{Melanie Figtree}

Resident Medical Officer

Royal North Shore Hospital

Malaria is the most common tropical parasitic infection imported into NSW. This article presents a review of all cases of malaria diagnosed and notified in NSW and the Australian Capital Territory from 1989 to the end of 2003. Of the four species of malaria infecting humans, Plasmodium falciparum, $P$. vivax, $P$. ovale and $P$. malariae, $P$. falciparum is most likely to be associated with serious illness and death. Therefore, trends in the occurrence of this species over the period are examined. This information is of value to clinicians and public health professionals in highlighting both the importance of rapid and accurate diagnosis of malaria and the changing trends in the origin of imported cases.

This study uses data collected by the NSW Malaria Register. The register, which closed at the end of 2003, had its origins in the Australian Malaria Register that was established at the School of Public Health and Tropical Medicine, University of Sydney, in 1969. The NSW component

\section{TABLE 1}

NUMBER OF MALARIA INFECTIONS NOTIFIED IN NEW SOUTH WALES AND THE AUSTRALIAN CAPITAL TERRITORY, 1989-2003

\begin{tabular}{|cccc|}
\hline Year & $\begin{array}{c}\text { All malaria } \\
\text { species }(\boldsymbol{n})\end{array}$ & \multicolumn{2}{c|}{$\boldsymbol{P}$. falciparum infections } \\
\cline { 3 - 4 } & & $\boldsymbol{n}$ & $\%$ \\
\hline 1989 & 149 & 38 & 25 \\
1990 & 202 & 50 & 25 \\
1991 & 230 & 52 & 23 \\
1992 & 193 & 38 & 20 \\
1993 & 226 & 42 & 19 \\
1994 & 231 & 62 & 27 \\
1995 & 206 & 49 & 24 \\
1996 & 261 & 50 & 19 \\
1997 & 213 & 66 & 31 \\
1998 & 189 & 50 & 26 \\
1999 & 220 & 63 & 29 \\
2000 & 248 & 49 & 20 \\
2001 & 197 & 54 & 27 \\
2002 & 145 & 43 & 30 \\
2003 & 164 & 53 & 32 \\
\hline Source: NSW Malaria Register & & \\
\hline
\end{tabular}

became a separate entity, maintained at the Centre for Infectious Diseases and Microbiology, Westmead Hospital, in 1988, shortly after the School of Public Health and Tropical Medicine closed in 1987.

\section{METHODS}

This is a retrospective case series of all microscopically confirmed malaria infections notified in NSW and the Australian Capital Territory between 1989 and 2003. Blood films from all notified malaria infections were sent to the NSW Malaria Reference Laboratory (at the Institute for Clinical Pathology and Medical Research, Westmead Hospital) for confirmation of diagnosis. The accuracy of the original diagnosis was assessed by an expert malaria microscopist who reviewed all submitted films and reported back to the referring laboratory, thus providing quality assurance on malaria diagnosis. Additional information about the patient's illness was obtained by sending the referring doctor a form to complete.

The information collected about each case included the geographic region in which the illness was acquired, the interval between onset of symptoms and diagnosis, accuracy of species identification, parasite count, and prophylaxis usage. Disease outcome was classified as nonsevere, severe, or fatal. Severe infections were those where the patient required admission to an intensive care unit.

The information describing the geographic origin of infections was categorised into eight regions based on epidemiological rather than political criteria. For example, the geographic region 'Australasia' used here includes Papua New Guinea, the Solomon Islands, Vanuatu, West Papua and Australia, a grouping based largely on the similarity of the Anopheles vectors in the region.

Data were analysed using EpiInfo Version 6.04 and Statcalc. During the period of the study 85 per cent of questionnaires sent to referring doctors were completed. To avoid distortion of the results of analyses, cases for which information on a factor was missing (date of onset, for example), were excluded from the analysis of that factor.

The efficacy of chemoprophylaxis was examined through the analysis of information describing its use by 592 Australian citizens who acquired malaria in Papua New Guinea. This group was selected because Australian citizens would almost certainly be non-immune to malaria and are likely to have received some pre-travel advice regarding the use of malaria prophylaxis. The analysis was restricted to malaria acquired in Papua New Guinea to minimise variability in transmission patterns between geographical regions, which have different vector species. 


\section{RESULTS}

There were 3,074 malaria infections notified in NSW for the period. The number of notifications for each year is presented in Table 1.

Information describing the geographic location where the patient acquired their infection was available for 2,933 (95\%) cases (see Table 2). Forty per cent of the imported cases came from Papua New Guinea.

The proportion of cases imported from Africa increased significantly from 14 per cent in 1995 to 23 per cent in 1996 and this increase has persisted (see Table 3$)($ Chi square $=$ $38.9 ; \mathrm{p}=0.000)$.

Three infections of Plasmodium vivax were acquired locally: two congenital infections occurred in infants born in Sydney to mothers born overseas, and one infection diagnosed in Sydney was acquired in far north Queensland in 2002.

\section{Species of imported malaria}

All four species of human malaria are imported into NSW, but Plasmodium vivax is the most common. The numbers of notifications involving each species are presented in Table 4 . There were 13 blood films referred to the reference laboratory in which the species could not be determined, either because there was a very low density of parasites or the blood film was of a poor quality. These infections are listed in the table as indeterminate species.

\section{Reason stated by patient for their presence in malarious country}

The reasons cited by patients for being in a malarious country were available for 2,648 cases and are summarised in Table 5. Most people acquire malaria while travelling overseas on holiday.

\section{$\boldsymbol{P}$. falciparum infections}

Table 1 presents the number of notifications of $P$. falciparum infections in NSW for each year in the period 1989 to 2003; it also presents the notifications as a proportion of all malaria infections that were notified in each year. Analysis of these data for a linear trend reveals there has been a slight but significant increase in the proportion of $P$. falciparum infections over the period (Chi square $=6.07 ; \mathrm{p}=0.014$ ).

\section{Severity of infections}

In individuals who are not immune to malaria there is usually a direct relationship between the density of parasitaemia and the severity of infections with $P$. falciparum. Parasite density counts were available for 209 P. falciparum infections and these were stratified as to the severity of the infection (see Table 6). There was a significant relationship (chi square 46.7; $\mathrm{p}=0.000$ ) between the severity of the illness and the percentage of red blood cells infected with parasites. There were three deaths due to malaria in this period.
TABLE 2

GEOGRAPHIC REGION OF ORIGIN OF IMPORTED MALARIA INFECTIONS IN NEW SOUTH WALES AND THE AUSTRALIAN CAPITAL TERRITORY 1989-2003 AND PROPORTION OF P. FALCIPARUM

\begin{tabular}{|lrcc|}
\hline $\begin{array}{l}\text { Geographic } \\
\text { region }\end{array}$ & $\begin{array}{c}\text { All malaria species } \\
\boldsymbol{n}\end{array}$ & $\begin{array}{c}\text { Proportion of } \\
\text { P.falciparum (\%) }\end{array}$ \\
\hline Australasia & 1,506 & 51.0 & 21 \\
South East Asia & 552 & 19.0 & 18 \\
Africa & 469 & 16.0 & 62 \\
Southern Asia & 378 & 13.0 & 6 \\
Central America & 14 & 0.5 & 7 \\
South America & 7 & 0.2 & 14 \\
East Asia & 4 & 0.1 & 0 \\
West Asia & 3 & 0.1 & 0 \\
\hline Source: NSW Malaria Register & & \\
\hline
\end{tabular}

TABLE 3

COMPARISON OF PROPORTION OF MALARIA CASES IMPORTED FROM AFRICA AND OTHER REGIONS FOR THE PERIODS 1989-1995 AND 1996-2003

\begin{tabular}{|lcccc|}
\hline Years & \multicolumn{2}{c}{ Africa } & \multicolumn{2}{c|}{ Other regions } \\
& $\boldsymbol{n}$ & $\%$ & $\boldsymbol{n}$ & $\%$ \\
\hline $1989-1995$ & 160 & 11.5 & 1,227 & 88.5 \\
$1996-2003$ & 309 & 19.9 & 1,237 & 80.1 \\
\hline \multicolumn{2}{l}{ Source: NSW Malaria Register } \\
\hline
\end{tabular}

\section{TABLE 4}

SPECIES OF IMPORTED MALARIA IN NSW, 1989-2003

\begin{tabular}{lc|} 
Malaria species & Infections $(\boldsymbol{n})$ \\
\hline Plasmodium falciparum & 737 \\
P. falciparum and P. malariae & 1 \\
P. falciparum and P. ovale & 3 \\
P. falciparum and P. vivax & 18 \\
P. vivax & 2,163 \\
P. vivax and P. malariae & 1 \\
P. ovale & 95 \\
P. malariae & 43 \\
Indeterminate species & 13 \\
Total & 3,074 \\
Source: NSW Malaria Register &
\end{tabular}

\section{Onset of illness}

For most cases of malaria ( 88 per cent) the onset of symptoms occurred after the patient had arrived in Australia. However, in 27 per cent of infections with P. falciparum, the onset of illness occurred while the patient was overseas. The interval between onset of symptoms and diagnosis was slightly longer for the severe or fatal infections (median 6 days) than for the non-severe $P$. falciparum infections (median three days) $($ Chi square $=10.7, \mathrm{df}=1, \mathrm{p}=0.00)$. 
TABLE 5

REASON STATED BY THE PATIENT FOR THEIR PRESENCE IN MALARIOUS COUNTRY

\begin{tabular}{|lrr|}
\hline Reason for presence in malarious country & $\boldsymbol{n}$ & $\begin{array}{c}\text { Patients with } \\
\text { P. falciparum }\end{array}$ \\
\hline Holiday travel & 913 & 34 \\
Business travel or employment or companion & 716 & 26 \\
Resident of malarious country visiting or emigrating to Australia & 625 & 30 \\
Resident of Australia visiting relatives in country of birth & 233 & 24 \\
Education-related travel to malarious country & 27 & 9 \\
Other reason (including travel as member of Australian Defence Forces) & 134 & 1 \\
\hline Source: NSW Malaria Register & & 5 \\
\hline
\end{tabular}

\section{TABLE 6}

MEDIAN PARASITE DENSITY FOR P. FALCIPARUM INFECTIONS AND SEVERITY OF INFECTION IN 209 PATIENTS

\begin{tabular}{|lcc|}
\hline $\begin{array}{l}\text { Clinical severity of ma- } \\
\text { laria infection }\end{array}$ & $\begin{array}{c}\text { Number of } \\
\text { patients }\end{array}$ & $\begin{array}{c}\text { Percentage } \\
\text { of red blood } \\
\text { cells infected }\end{array}$ \\
\hline Severe and fatal infections & 25 & 9.9 \\
Non-severe infections & 184 & 0.4 \\
\hline Source: NSW Malaria Register & & \\
\hline
\end{tabular}

\section{TABLE 7}

\section{PROPHYLAXIS USAGE AMONG PATIENTS WITH MALARIA}

\begin{tabular}{|lcccc|}
\hline Patients & \multicolumn{3}{l|}{ Took } & \multicolumn{2}{c|}{ Took no } \\
& prophylaxis & \multicolumn{2}{c|}{ prophylaxis } \\
& $\boldsymbol{n}$ & $\%$ & $\boldsymbol{n}$ & $\%$ \\
\hline Infected with P. falciparum & 53 & 12 & 41 & 26 \\
Infected with another species & 380 & 88 & 118 & 74 \\
\hline Source: NSW Malaria Register & & & & \\
\hline
\end{tabular}

\section{Diagnosis}

The diagnostic error rate was higher for cases with $P$. falciparum (15 per cent incorrect) than for other species of malaria (eight per cent). The most frequent error ( 22 per cent of total) was $P$. falciparum being identified as $P$. vivax. In seven per cent of misdiagnoses the infection was missed at the initial examination of the blood film, but subsequently detected by another laboratory.

\section{Prophylaxis usage}

For the 592 Australian citizens who acquired malaria in Papua New Guinea, the risk of acquiring P. falciparum was significantly greater for those who did not use prophylaxis (see Table 7) $($ Chi square $=15.98 ; \mathrm{p}=0.000)$.

The highest rate of $P$. falciparum infections occurred in patients who had visited relatives in their country of birth (Table 5); of these 62 per cent were not taking prophylaxis, compared with 41 per cent of patients who did not take prophylaxis when travelling for other reasons.

\section{DISCUSSION}

Malaria is a laboratory notifiable infection in all states and territories in Australia. It is likely that most infections are reported. In the case of the infections notified to the NSW Malaria Register, this was highly probable because the referring laboratories received free quality assurance on their diagnostic capability. Although it was not mandatory for referring doctors to provide information concerning their patients, the majority did return the questionnaire.

Despite decades of attempts at control, P. falciparum remains one of the major causes of death in the world and non-immune travellers are especially vulnerable. ${ }^{1}$ This species is widely distributed in tropical and sub-tropical regions but is particularly prevalent in African countries. Hence, travellers to that continent are more likely, if they become infected with malaria, to acquire P. falciparum. Whether the increase in infections imported from Africa that has persisted since 1996 is due to increased travel to the region or to the deteriorating malaria situation there, is not known.

One issue of concern is the frequency with which travellers become ill with $P$. falciparum whilst still overseas. The signs and symptoms of this infection are non-specific and mimic common illnesses such as influenza, making it likely that some individuals will not seek medical attention as soon as they would in their home environment.

The major risk factor for developing severe malaria is a delay in the diagnosis and in establishing appropriate management. ${ }^{2}$ In this study the median time between the onset of symptoms and diagnosis for non-severe infections was three days, while for the severe and fatal infections the interval was six days. This delay often occurred because the patient had not sought medical attention. However, in one of the three fatal infections no blood films were made at the initial presentation despite the patient providing a suggestive history. The other two deaths illustrate the unpredictable nature of $P$. falciparum infections. In each, the diagnosis was made and initially successful management begun. However, both patients suddenly and unexpectedly deteriorated and died.

The much higher density of parasitaemia in the patients with severe and fatal infections attests to the need for early 
diagnosis and treatment. Consequently, the high diagnostic error rate, especially that involving $P$. falciparum, is of concern. In six of the 25 severe infections the diagnosis was initially incorrect. New, rapid diagnostic tests specific for $P$. falciparum should help address this problem. ${ }^{3}$ The difficulty that some laboratories have with malaria diagnosis highlights the contribution that can be provided by a diagnostic reference laboratory.

The increasing drug resistance of malaria parasites and the breakthroughs in illness that occur following incorrect use of prophylaxis have led to suggestions that anti-malarial prophylaxis is not efficacious. While prophylaxis cannot prevent late onset infections with $P$. vivax or $P$. ovale ${ }^{4}$, the findings presented here for Australian citizens travelling to Papua New Guinea strongly support its use for protection against $P$. falciparum.

Previous residents of malarious regions who have emigrated to developed countries such as Australia are at risk of acquiring malaria when they visit their previous home. ${ }^{5}$ Interventions for these groups could include information about the prevention of malaria to be included in ethnic language newspapers or television networks, and in local medical centres.

There has been a recent decline in the total number of malaria infections notified in NSW. There has, however, been an increase in the number of infections acquired in Africa and because most of these are caused by the potentially fatal $P$. falciparum, malaria must remain high on the list of differential diagnoses for febrile travellers.

\section{REFERENCES}

1. World Health Organization. International travel and health. Geneva, World Health Organization, 2002.

2. World Health Organization. Severe falciparum malaria. Trans R Soc Trop Med Hyg 2000 Apr; 94 Suppl 1: S1-90.

3. Playford EG, Walker J. Evaluation of the ICT Malaria P.f/P.v and the OptiMal rapid diagnostic tests for malaria in febrile returned travellers. J Clin Microbiol 2002; 40(11): 4166-71.

4. Taylor T, Strickland G. Malaria. In: Strickland G, editor Hunter's tropical medicine and emerging infectious diseases, $8^{\text {th }}$ edition. Philadelphia: WB Saunders Company, 2000: 614-42.

5. Phillips-Howard PA, Bradley DJ, Blaze M, Hurn M. Malaria in Britain: 1977-86. BMJ 1988; 296: 245-8. 용

\section{HEALTH IMPACT ASSESSMENT COLLOQUIUM: 9 DECEMBER 2005}

The Centre for Health Equity Training, Research and Evaluation (CHETRE), in conjunction with the NSW

Department of Health, is holding a colloquium on health impact assessment in NSW. The colloquium will provide an opportunity for anyone with an interest in health impact assessment to meet, network and learn from others.

The colloquium will address a range of issues including:

- What can we learn from the health impact assessments that have been undertaken?

- How can we build collaboration within and beyond the health sector to undertake health impact assessment?

- How does health impact assessment relate to other forms of assessment such as social impact assessment or environmental impact assessment?

- How are we building capacity?

The colloquium will be of interest to anyone who works with or wants to know more about health impact assessment; for example, workers in population health, local government, health promotion, urban planning and environmental health; health service planners; clinicians; community and allied health professionals; Aboriginal health workers; students; academics and community representatives.

\section{DATE}

Friday 9 December 2005, 9:00am-5:00pm

\section{VENUE}

Swiss Grand Hotel, Corner Campbell Parade and Beach Road, Bondi, NSW

\section{COST}

$\$ 50$, including lunch

For more information please visit http://chetre.med.unsw.edu.au/hia/colloquium.htm or telephone (02) 98286230. 